\title{
Treatment of A Boy with Idiopathic Mental Retardation: From Uneducable to Educable
}

\author{
Aamir Jalal Al-Mosawi* \\ Advisor in Pediatrics and Pediatric Psychiatry, Children Teaching Hospital of Baghdad Medical City. \\ *Corresponding author: Aamir Jalal Al-Mosawi, Children Teaching Hospital of Baghdad Medical City, Baghdad, Iraq.
}

\begin{abstract}
Background: Mental retardation has been recently called by the American Psychiatric Association "Intellectual disability", despite that the World Health Organization is still using the term "Mental retardation" in its ICD-10 publication. It is a heterogeneous condition marked by generalized neurodevelopmental abnormalities associated with significant impairment in mental or intellectual functioning and adaptive behaviors that affect every day general living.

Patients and Methods: A comprehensive multi-factorial treatment approach was used to treat a boy with idiopathic (Moderate to severe) mental retardation who was uneducable with the main aim of making him more educable. Treatment courses included intramuscular citicoline, piracetam, cerebrolysin, and oral pyritinol.

Results: Treatment was successful in advancing the mental and cognitive functions of the patient and making the child perfectly educable.

Conclusion: There is no single agent that is known to convert an educable mentally retarded child to perfectly educable. Idiopathic mental retardation is a heterogeneous condition and the use of multi-factorial therapeutic agents is suggested for its treatment.
\end{abstract}

\section{Introduction}

Mental retardation is heterogeneous a condition marked by generalized neurodevelopmental abnormalities associated with significant impairment in mental or intellectual functioning and adaptive behaviors that affect everyday general living. Adaptive behaviors or adaptive skills are needed to live independently or at the minimally acceptable level for age. They are assessed by comparing the functional abilities of a child with other children of similar age. They include:Daily living skills such as feeding self, dressing, using the bathroom and dressing / undressing. Social skills and communication skills such as understanding what is said and being able to answer.Although the World Health Organization is still using the term "Mental retardation" in its ICD-10 publication, the American Psychiatric has recently called the condition "Intellectual disability".There are two main types of mental retardation;
Syndromic type associated with other abnormalities which occur in conditions such as Down syndrome. Non-syndromic or idiopathic type which is not associated with other abnormalities.

\section{Common manifestations of mental retardation include:}

Delays or failure in achieving motor developmental milestones (sitting, crawling, walking). Delayed speech and difficulties with language skills after starting to talk. Difficulties with self-help and self-careskills including self-feeding, washing, and dressing/ undressing. Behavioral and social problems. Failure ofschool education [1-3]. The aim of this paper is to retrospectively describe the treatment of a boy with uneducable (Moderate to severe) idiopathic mental retardation with the aim of making him more educable. A five- and eight-months old boy was brought to the pediatric neuropsychiatry clinic because of markedly delayed 
speech, impaired adaptive skills, and abnormal behaviors. The boy was unable able to perform daily activities such going to bathroom independently and washing his hands. He was born more than 10 days post-term by caesarean section and had low birth weight: two kilograms according to the mother.His parents were cousins. His father was a construction worker who was born in 1982. His education was limited to finishing primary school. The mother was a 38-year housewife and her education was also limited to finishing primary school. The boy was saying only few words and was not saying any two-words sentence.He could say the names of his brother and two sisters (A normal child says at least 6 intelligible words at the age of eighteen months, and a normal child joins two-three words in sentences at the age of two years, and normal child speaks in sentences and gives full name at the age of three years[1-3]).He didn't say Baba and Mama until around the age of two years (A normal child says Dada and Mama non-specifically at ten months, and Dada and Mama specifically at one year of age[1-3]). The mother thought that the boy was not smiling nor responding to his name during the first year of life (A normal infant smiles responsively at 6-8 weeks[1-3]) , and he was also not looking much to her face (A normal infant looks at mother $\mathrm{s}$ face at two weeks of age[1-3]).

He was also unable to understand simple commands at one year of age (A normal infant understand simple commands at twelve months [1-3]).The boy's motor developmental milestones were achieved relatively late. He walked holding furniture at around the age of eighteen months (A normal child can walk alone at the age of eighteen months [1-3]).However, currently, he can run, and climb stairs normally (A normal child can run at two years, normal child can walk upstairs two feet to a step at two years, and normal child

Table 1: A multi-factorial treatment approach. can walk upstairs alternating feet at three years, and Walks upstairs one foot per step and downstairs two feet to a step[1-3]).The boy could eat independently, but he could not wash his hands nor brush his teeth (A one-year old child can drink from a cup, a normal child can drink from cup using 2 hands at eighteen months, and a normal child can use spoon at two years and uses spoon well without much spilling at three years [1-3]).He was not controlling bowels and could not go to bathroom independently (A two-year old child can indicate need for toilet while a five-year old child can wash and dry face and hands[1-3]).

On presentation, he was responding to his name, approaches others; engage in games with other children. He was also waving goodbye, clap, and could use also use nonverbal communication (movements) to indicate what he wants and can imitate others. He was understanding facial expressions and could make friendship with other children. The boy also had some abnormal behaviors like beating and clinching his mother, hitting things, and threatening to break things when angry. Although he was playing some games on cell phone, he doesn't hold a pencil or scribble. At the clinic, the boy was not cooperative and didn't respond to any questions and didn't like taking photo, he tried to escape from the examination room (Figure 1). He didn't accept taking a pen to scribble or write something (A normal child scribbles at the age of eighteen months, and copies line at the age of eighteen months. A normal child copies a circle at three years, and copies a cross and a square at four years. A normal child copies a triangle at the age of five years [13]). The boy was treated with a multi-factorial treatment approach consisting of two courses (Table 1). The parents were asked to get him a copybook and try to teach him to draw a line, circle, a square.

\section{The first treatment course}

Citicoline $375 \mathrm{mg}$ given by intra-muscular injections every three days (5doses)

Piracetam $600 \mathrm{mg}$ given by intra-muscular injections every three days (5doses)

Oral pyritinol $60 \mathrm{mg}$ daily

The second treatment course

Cerebrolysin $1 \mathrm{ml}$ given by intra-muscular injections every three days ( 9 doses).Oral pyritinol 60 mg daily

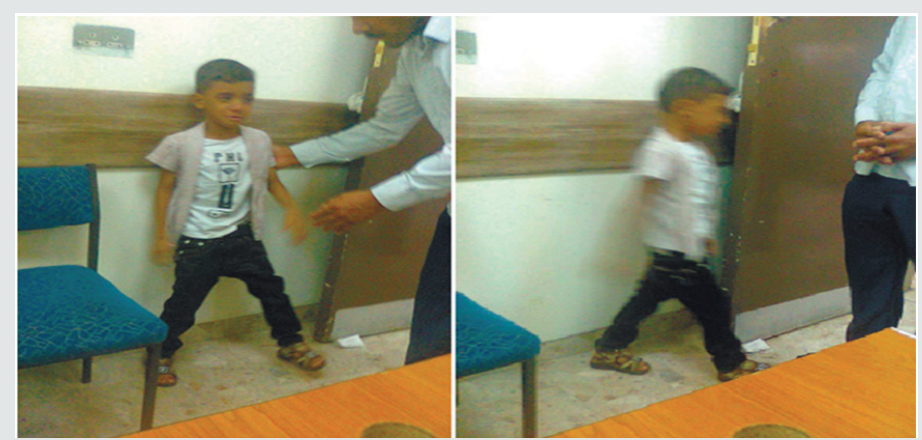

Figure 1: At the clinic, the boy was not responsive to any questions and didn't like taking photo and tried to escape from the examination room. 


\section{Results}

After the first course of treatment, the child was still not that cooperative, but he responded to calling his name by turning his head. The mother was happy that treatment enabled her to convince him not to drink much at night, and she was thus successful in keeping him dry at night. However, he was still not controlling bowels. The family was able to teach him many things. They brought his drawings at home. His drawings included a circle, a square, the sun, a flower, and a face (Figure 2A). He was also saying two-word sentences to express some needs. At the clinic, and with help of the family, he accepted to write and draw. He copied a line, a circle, and numbers one, two, four, and five. He was also successful in drawing a man. He also tried to copy his name (Figure 2B).

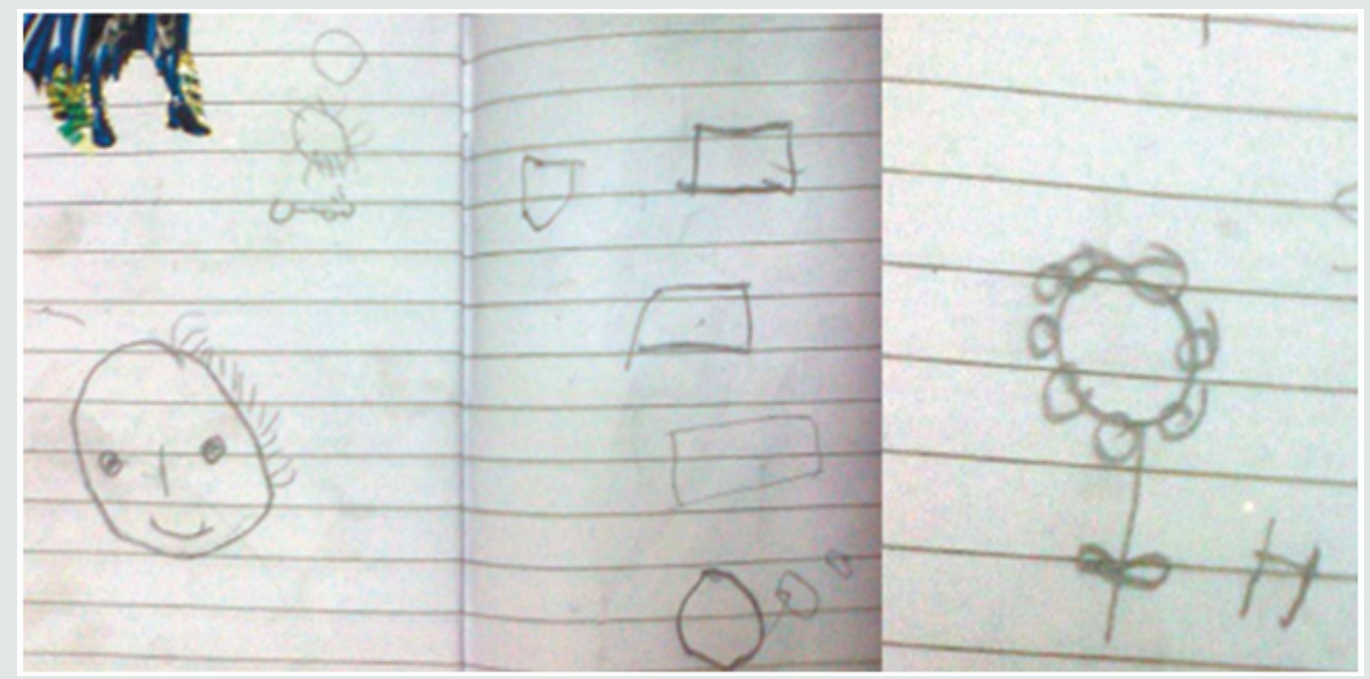

Figure 2A: The child s drawings at home included a circle, a square, the sun, and a face.

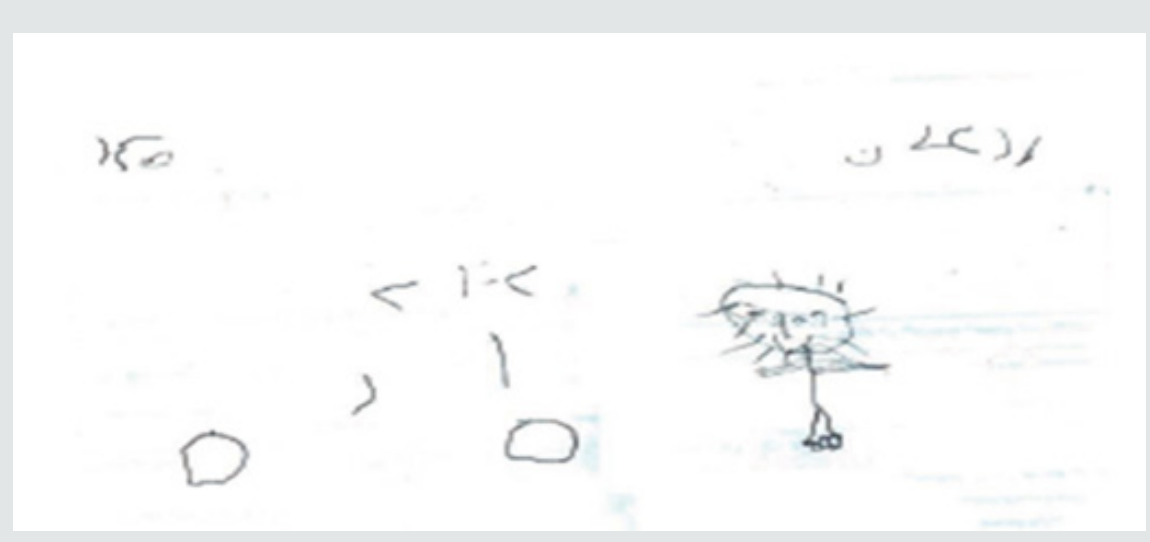

Figure 2B: At the clinic, he copied a line, circle, and numbers one, two, four, and five. He was also successful in drawing a man. He also tried to copy his name.

After the second course, the parents reported significant improvement of his behaviors with marked reduction of abnormal behaviors and significant improvement in his ability and desire to learn. His vocabulary was markedly expanded, and he was saying many sentences. His learning book included many Arabic letters, numbers, forms (a square, a triangle) and pictures including sun, flower, an 0 clock, a butterfly, a boy, a flag, a bird, a ladder, a door, a cup, a cloud raining, and his name (Figure 3).At the clinic, the boy's behavior was markedly improved when compared to his behavior before starting treatment. The boy was calm and was obviously focused, he sat on the chair looking at the doctor and listening to him while he was interviewing his mother. It was very easy to make him come near the doctor to draw and write and to take him photos (Figure4A). He wrote his name which was good and easily readable, he also wrote some Arabic letters (Some of them were not good); he was able to draw a square, a sun, and a flower (Figure 4B). 


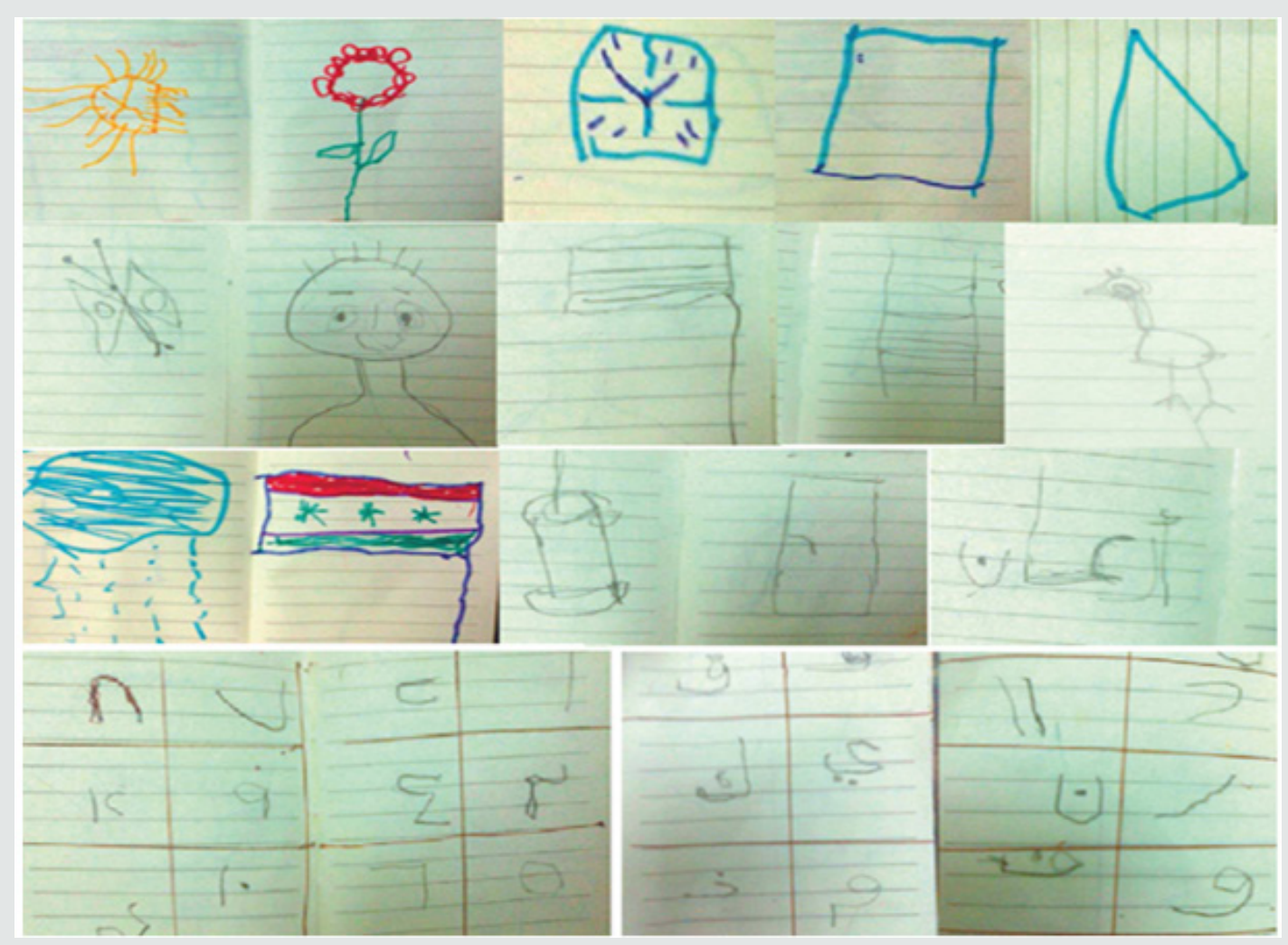

Figure 3: After the second course, his learning book included many Arabic letters, numbers, forms (a square, a triangle) and pictures including sun, flower, an O clock, a butterfly, a boy, a flag, a bird, a ladder, a door, a cup, a cloud raining, and his name.
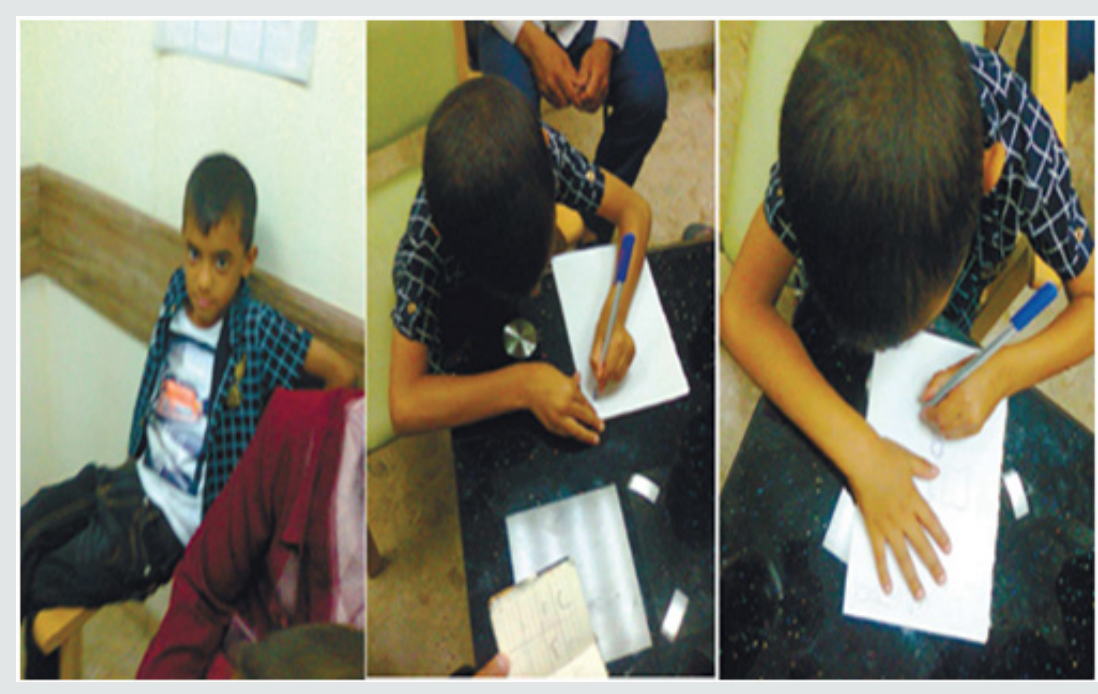

Figure 4A: At the clinic, the boy's behavior was markedly improved when compared to his behavior before starting therapy. The child was calm and was obviously focused, he sat on the chair looking at the doctor and listening to him while he was interviewing his mother. It was very easy to make him come near the doctor to draw and write and to take him photos. It was very easy to make him come near the doctor to draw and write and to take him photos. 


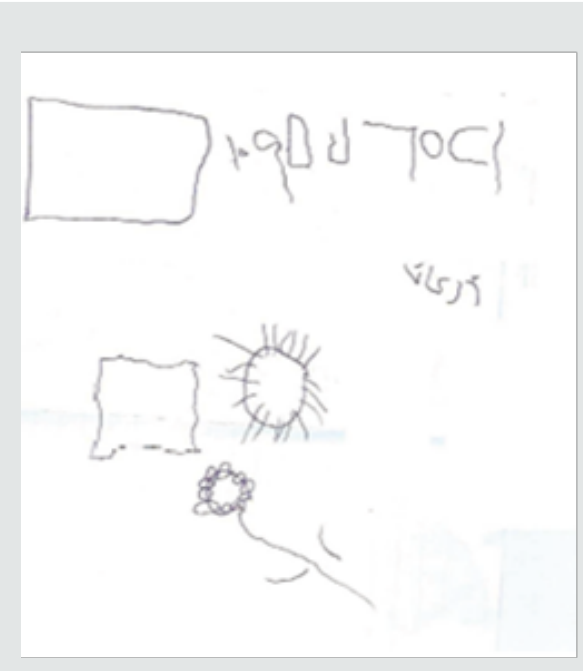

Figure 4B: At the clinic, he wrote his name which was good and easily readable, he wrote some Arabic letters (Some of them were not good), he was able to draw a square, a sun, and a flower.

\section{Discussion}

Patients with idiopathic (Non-syndromic) mild mental retardation (IQ: 50-70) may escape diagnosis during the preschool period and they generally don't have problems with selfcare and practical skills. Patients with moderate mental (IQ: 35-49) are generally identified during the preschool period and delayed speech is a common manifestation of moderate mental retardation. Such individuals have limited chance in making progress in school education.Mental retardation is associated with significant disability that is attributed to the mental impairment, and there is no known therapeutic approach than can advance the mental function to move the patient from the educable to uneducable mental retardation.Mental functions in mentally retarded children have been linked practicably by educability. Individuals with mild mental retardation (IQ: 50-70) are considered to be educable and have the chance to progress to a late grade of elementary. Individuals with moderate and severe mental retardation (IQ below 50) are generally not educable, but they can be trainable [1-5].Citicoline is a mononucleotide made of ribose, pyrophosphate, cytosine and choline. It is a water-soluble naturally occurring substance that is generally grouped with the B vitamins. It is also considered a form of the essential nutrient choline [6-8]. Citicoline has been recently used with benefit in treatment of childhood neuro-psychiatric disorders including, pervasive developmental disorders (including Rett syndrome) [8-11], brain atrophy [12], kernicterus [13], and cerebral palsy [14-16].

Piracetam can beneficially influence impaired brain function by improving neuronal and cognitive functions without acting as a sedative or stimulant, increasing blood flow and oxygen consumption in the brain, and improving the function of the neurotransmitters and brain neurotransmission. The modes of action of piracetam has been attributed to differential effects on subtypes of glutamate receptors without GABAergic actions Piracetam has no significant side effect nor has acute toxicity at the doses used in human studies. The LD50 is $5.6 \mathrm{~g} / \mathrm{kg}$ in rats and $20 \mathrm{~g} / \mathrm{kg}$ in mice, indicating extremely low acute toxicity [14-19].Cerebrolysin has recently been safely used in the treatment of a variety of childhood neurological and psychiatric disorders including brain atrophy [12], cerebral palsy [14-16], kernicterus [13], agenesis of the corpus callosum [18], pediatric juvenile spinal muscular atrophy [20], Charcot Marie Tooth disease[21], myelomeningocele [22], autism, and Rett syndrome [8-11]. Pyritinol, a pyrithioxine derivative, is a semisynthetic water-soluble analog of vitamin B6 (Pyridoxine $\mathrm{Hcl}$ ). It has been shown that cerebral blood supply is increased by pyritinol resulting in an improvement of nerve cell metabolism, and it was used with benefit in cerebral palsy [12-23].

\section{Conclusion}

In this illustrative study, the use of a multi-factorial treatment approach to improve brain function, cognition, and educability resulted an obvious beneficial effect.

\section{Acknowledgement}

The author would like to acknowledge his gratitude for the parents who willingly accepted publishing the photos of their children.

\section{Conflict of interests: None.}

\section{References}

1. Al Mosawi AJ (2018) Pediatric psychiatry: An accredited training course. $1^{\text {st }}$ ed., Saarbrücken; LAP Lambert Academic Publishing ISBN: 978-6139-86510-9.

2. Al Mosawi AJ (2019) The pattern of mental retardation in Iraqi children. $1^{\text {st }}$ ed., Saarbrücken. LAP Lambert Academic Publishing ISBN: 978-613-9-47350-2.

3. Al Mosawi AJ (2020) Case studies in pediatric psychiatry an approach to deep learning. $1^{\text {st }}$ ed., Saarbrücken; LAP Lambert Academic Publishing ISBN: 978-620-2-52071-3.

4. Al Mosawi AJ (2020) Il modello del ritardo mentale nei bambini iracheni Psichiatria infantile (Italian Edition). Edizioni Accademiche Italiane ISBN-10: 620083721X, ISBN-13: 978-6200837219.

5. Al Mosawi AJ (2020) Das Muster der mentalen Retardierung bei irakischen Kindern Kinderpsychiatrie (German Edition). AV Akademikerverlag ISBN-10: 6200670757, ISBN-13: 978-6200670755.

6. Al Mosawi AJ (2019) Citicoline research progress. $1^{\text {st }}$ ed., Saarbrücken. LAP Lambert Academic Publishing ISBN: 978-620-0-11372-6.

7. Al Mosawi AJ (2019) The Use of Citicoline in Pediatric Neurology and Pediatric Psychiatry. Austin Pediatrics (ISSN: 2381-8999) 6(1): 10711072.

8. Al Mosawi AJ (2019) The use of cerebrolysin and citicoline in autism and Asperger syndrome. J Bio Innov 8(1): 99-108.

9. Al Mosawi AJ (2019) New therapies for Rett syndrome. J Bio Innov 8(3): 301-307. 
10. Al Mosawi AJ (2018) A new therapeutic approach for pervasive developmental disorders. $1^{\text {st }}$ ed., Saarbrücken; LAP Lambert Academic Publishing ISBN: 978-3-659-86602-9.

11. Al Mosawi AJ (2020) Cure of autistic disorders: Our unique experience $.1^{\text {st }}$ ed., Saarbrücken; LAP Lambert Academic Publishing ISBN: 978-6202-67716-5

12. Al Mosawi AJ (2020) The Treatment of a Child with Birth Asphyxia Induced Brain Atrophy, Adrenal Hemorrhage, and Bi-lateral Hyperoxaluric Nephrocalcinosis: A Challenging Case and a Unique Experience. Open Access Journal of Biogeneric Science and Research (ISSN: 2692-1081) 2(2): 1-6.

13. Al Mosawi AJ (2019) The novel use of cerebrolysin and citicoline in the treatment of kernicterus. Online Journal of Neurology and Brain Disorders (ISSN: 2637-6628) 3 (1): 208-212.

14. Al Mosawi AJ (2019) New therapies for the treatment of spastic cerebral palsy $1^{\text {st }}$ ed., Saarbrücken; LAP Lambert Academic Publishing (ISBN 978-620-0-00321-8).

15. Al Mosawi AJ (2019) The Pattern of Cerebral Palsy in Iraqi Children. $1^{\text {st }}$ edn., Saarbrücken; LAP Lambert Academic Publishing (ISBN: 978-6200-09427-8).

16. Al Mosawi AJ (2019) New Therapies for the treatment of spastic cerebral palsy. Med J Clin Trials Case Stud 3(2): 000209.
17. Al Mosawi AJ (2020) Recent Uses of Piracetam in Pediatric Neurology. SunKrist Neurology, Neurosurgery and Stroke Journal 2(1): 1002(1-5).

18. Al Mosawi AJ (2020) The use of piracetam and cerebrolysin in the treatment of agenesis of corpus callosum with colpocephaly. EC clinical and medical case reports 3(1): 01-05.

19. Al Mosawi AJ (2017) A new therapeutic approach for the treatment of brain atrophy. $1^{\text {st }}$ edn., Saarbrücken; LAP Lambert Academic Publishing (ISBN: 978-620-2-07438-4).

20. Al Mosawi AJ (2020) The use of cerebrolysin in pediatric Wohlfart Kugelberg Welander syndrome. MOJ Clinical \& Medical Case Reports 10(1): 20-23.

21. Al Mosawi AJ (2020) The use of Cerebrolysin in Pediatric Charcot Marie Tooth Disease. Journal of neurological research and therapy 3(2): 17-21.

22. Al Mosawi AJ (2019) New medical therapies for the treatment of myelomeningocele. Surgical Medicine Open Access Journal (ISSN: 25780379) 2(4): 1-4.

23. Al Mosawi AJ (2020) The Experience with the Use of Nandrolone Decanoate and Pyritinol in Children with Cerebral Palsy. Open Access Journal of Biogeneric Science and Research (ISSN: 2692-1081) 2(3): 1-3.

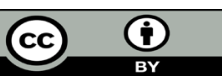

This work is licensed under Creative Commons Attribution 4.0 License

To Submit Your Article Click Here:

Submit Article

DOI: $10.32474 /$ PAPN.2020.02.000149

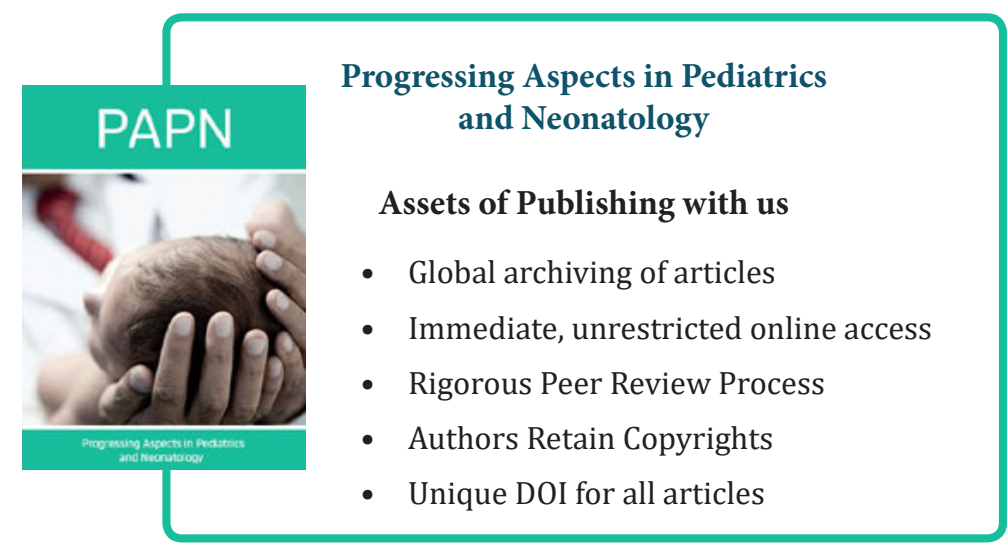

